\title{
Supporting and Changing Practices of Nested and Overlapping Educational Communities
}

\author{
Daniel Suthers, Violet Harada, Joyce Yukawa, and Viil Lid \\ Department of Information and Computer Sciences \\ University of Hawai i \\ \{suthers,vharada,yukawa,viil\}@hawaii.edu
}

\begin{abstract}
Applications of information technology to support systemic reform in public school systems have taken several forms. Instructional applications include attempts to more effectively convey information to students, to empower students' own agency in accessing information and constructing knowledge, and to aid teachers' classroom management, lesson preparation, and assessment. Technology has been proffered as a change agent in itself: teachers will need to change their practices in order to use technologies designed for doing authentic inquiry and communicating or collaborating with others (Soloway, 1996). Information technology can also support professional development through access to online courses, and enable participation in distributed communities of practice. The work reported in this paper has taken this latter strategy. Because today's school systems operate in an environment of constant change, professional development requires a paradigm shift from a scripted training approach to a more fluid approach that encourages the incorporation of networks, coalitions, and partnerships. The capacity to network with other professionals is essential to the notion of communities of practice. McLaughlin and Mitra (2001) argue that sustaining large-scale theory-based reform efforts "requires a community of practice to provide support, deflect challenges from the broader environment, and furnish the feedback and encouragement essential to going deeper" (p. 10). Barab (2003) defines a community that advances ongoing and open-ended professional development as a "persistent, sustained network of individuals who share and develop an overlapping knowledge base, set of beliefs, values, history and experiences focused on a common practice and/or mutual enterprise" (p. 198). These communities change the relationships among teachers, breaking the isolation that most teachers have found so confining.
\end{abstract}

Over the past several years, Hawai i Networked Learning Communities (HNLC), a National Science Foundation Rural Systemic Initiative (RSI), has been supporting communities of educators in Hawai i. The goal of HNLC is to empower educators to prepare students in economically disadvantaged rural schools for life and careers in today's complex and dynamic technological world by enabling them to attain high standards in science, mathematics, and technology (SMT). HNLC is the result of collaboration between the Department of Information and Computer Sciences (ICS) of the University of Hawai' $\mathrm{i}$ at Manoa (UHM) and the Advanced Technologies Research Branch (ATRB) of the Hawai i Department of Education (HIDOE). One component of our work is a "virtual community center," realized as a dynamic website (hnlc.org). We chose to use Internet technology to build and sustain a community of rural educators because they work in small and isolated schools separated by island geography. This website targets educators at two levels: teams of educators who are formally involved in HNLC, and the broader community of educational stakeholders in Hawai $\mathrm{i}$. The website includes a community forum for sharing news and stories of any nature deemed appropriate by members, and a database of Hawai i-based resources for education. Two additional tools are specifically intended to support the work of HNLC school teams: a template that guides unit planning, and an "artifact-centered" discussion tool for sharing and discussing work.

In the spring and early summer of 2003 (about 12 months after hnlc.org was first released), we undertook our first evaluation specifically targeted at determining levels of teacher use of our online community tools. This evaluation is summarized in Suthers et al. (2004). At the time of the evaluation, our work was focused on getting small teams of teachers to collaborate, online as well as face-to-face, to plan standards-based, assessment-driven and studentcentered inquiry units. Overall, respondents had positive attitudes about the use of technology in general for a range of purposes, but as of summer 2003 they had not made significant use of hnlc.org outside of sponsored events, with the exceptions of school teams preparing for those events and the initiative of a few individuals. Focus groups indicated some differences in the expectations of developers and users. The results of this study challenged us to rethink our efforts to use Internet technology in support of systemic reform. In this paper we summarize the most important portion of our deliberations concerning the community and practices to be supported. 
Prepublication draft of Suthers, D., Harada, V., Yukawa, J., \& Lid, V. (2005). "Supporting and changing practices of nested and overlapping educational communities. ACM SIGGROUP Bulletin 24 (3): 90-95.

\section{What Community Should Be Supported?}

Although our ultimate goal is increased student performance and participation in SMT, we want to accomplish this in a sustainable manner, which requires that we change the practices of those directly responsible for student learning rather than working directly with students ourselves. Therefore we reaffirmed that we want to support the work of teachers. Our working assumption from the outset has been that if teachers experienced the use of technology in their learning they would better understand how to use it for their students' learning. However, as discussed below, we found that we cannot neglect designing technology for use by students.

HNLC has been working with school teams formed for the purpose of representing each school to HNLC and developing an integrated unit plan as a model of how education could be done in their school. These teams may or may not be constituted of prior collaborators. An alternative approach is to identify existing communities within the schools (Kling \& Courtright, 2003) rather than leaving team formation up to school administrators. Regardless of how they are formed, school teams should enable educators of different disciplines or at different grade levels within a school to work with each other towards continuity in the students' learning experience across classes and grade levels.

We also recognize that relevant communities can extend beyond the schools. Teachers specializing in a given subject or grade level may want to network with each other across schools, forming communities of practice, the second "knit" of a double-knit organization (Wenger, McDermott \& Snyder, 2002). They may wish to discuss specific math and science projects being implemented on multiple campuses as well as applications for curriculum resources being used in various classrooms. There are also groups defined by administrative structures such as the HIDOE complexes (high schools and their primary and intermediate feeder schools). Collaboration within a complex could improve the educational experience from the students' point of view if innovations at the primary and secondary levels were coordinated. Finally, we considered whether our HNLC colleagues within the HIDOE should be the primary targets of our technology support. The ATRB team members plan the HNLC professional development program and carry it out in scheduled events, school visits, and online instruction. Although ATRB staff suggested that we focus on teachers, we recognize the need to work closely with the ATRB staff to ensure that the affordances of our technologies mesh well with their plans for professional development. For example, we found that because participants will most likely try new tools and practices at face-to-face training sessions organized by ATRB, we need to design for transitions between face-to-face and online use.

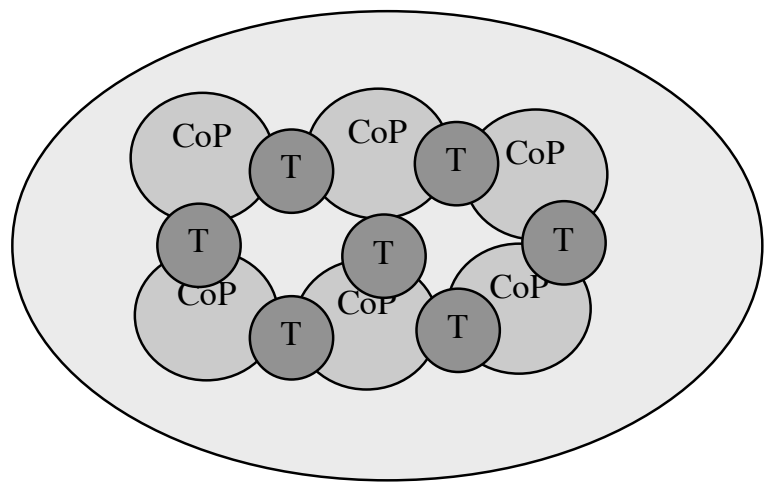

Figure 1. Nested and overlapping communities.

Members of school teams (T) interact with disciplinary peers via communities of practice $(\mathrm{CoP})$, all nurtured by the broader community of stakeholders (large ellipse). primary focus in the design of hnlc.org is now on both the school teams and on inter-school collaborations (communities of practice) in which educators and ATRB staff share ideas and advice (Figure 1). Our secondary focus remains on the larger community that forms the environment of resources and expectations within which our primary communities grow. Our working hypothesis is that it is essential for the sustainability of systemic reform that we not only address the needs of the practitioners whose work immediately impacts upon student performance, statewide community of SMT educators within HIDOE, and the even broader community of stakeholders and interested parties that includes parents, employers, and representatives of other federally funded programs that have an educational outreach component. The expectations and resources of these stakeholders are critical for shaping and sustaining the future of education.

Our efforts would be diluted if we tried to support all of these communities at once, but nor can we focus on school teams and ignore their context. We now believe that hnlc.org must selectively support nested and overlapping communities of practice (c.f., "nested learning communities," Resnick \& Hall, 1998; and "double-knit organizations," Wenger, McDermott \& Snyder, 2002) that extend beyond the schools and into the general community. We need to focus on teachers as those primarily responsible for student achievement, but not
neglect the larger community context of education. Our

Also of interest for our systemic reform agenda is the 
Prepublication draft of Suthers, D., Harada, V., Yukawa, J., \& Lid, V. (2005). "Supporting and changing practices of nested and overlapping educational communities. ACM SIGGROUP Bulletin 24 (3): 90-95.

but also initiate change in the broader community that places expectations on the school system as well as provides the resources to meet those expectations.

Discussions in the Community-Based Learning Workshop held at the 2004 International Conference on the Learning Sciences reinforced our view of the importance of nested communities and provided us with some fresh ideas about how we can support these communities. One way is through fostering a common identity and a culture of shared meaning and practices. A recent redesign of hnlc.org recognizes the importance of community awareness. Personal profiles displaying each member's community contributions serve to build their reputations within the community as well as facilitate finding other contributions by the same member (Kelly, Sung \& Farnham, 2002). Allowing the members to personalize their online presence by sharing information about themselves creates opportunities for finding others with similar interests or complementary skills, thus facilitating the forming of new collaborative connections and groups (Girgensohn \& Lee, 2002).

The concept of small group cognition helps clarify our focus on teacher teams. Small groups are the unit that mediates between individual learning and community learning (Stahl, in press), and therefore are the appropriate unit of action for systemic reform. Yet small groups do not exist in isolation: they form out of and are supported by communities. We are initiating a new effort to mobilize and support new members from the statewide community, with the expectation that this effort will foster new small communities of interest and that they will leverage resources provided by the larger community. We intend to study the interaction between the larger community, small communities and groups, and individual teachers in our target population to determine the effect of embedding in nested communities and how this is mediated by our technology.

\section{What Practice Should Be Supported?}

Having clarified the overlapping and nested spheres of communities of practice that we intend to support, we are still faced with the question, "What practice?" Should we design to meet practitioners' immediate needs and working practices (as conventional wisdom in human-computer system design suggests), even if that meant supporting existing teacher-centered forms of instruction?

We would be neglecting the systemic reform's objective of changing practice if we merely focused on supporting existing practice. Systemic reform requires that something sustainable change in the system beyond an immediate impact on this year's cohort of students. Furthermore, systemic reform means change, and that may mean trying to get educators to do things other than that which they think they most need. We need to change their practices as well as support them. The objective of this reform is a reflective-action form of practice - akin to action research - in which teachers use embedded assessment to examine the effects of their instructional interventions and the learning opportunities they create on student performance, and adjust those interventions and seek new opportunities as needed to improve performance. If this were the prevalent practice of our user community, then the tools that they need and indeed demand would be different than at present.

What role does technology play in driving the change process? Can we offer technology (integrated with professional development) that meets the demands of this imagined community of practice of the future, and thereby perturb the present activity system to change towards that future? This strategy will not work if educators don't use the tools, and they won't use tools that don't meet their present needs. Also, this approach presents a triple challenge: by asking teachers to (1) work collaboratively (2) via online technology (3) to plan and engage in studentcentered inquiry learning, we are asking them to do three things that most of them are not accustomed to doing. If teachers have not engaged in reflective discussion even in face-to-face settings, it is unrealistic to expect this behavior in an online environment (Kling and Courtright, 2003). Where do we begin?

Our hope is that the distinction between supporting and changing practice may be artificial or irrelevant, if the tools we offer are amenable to supporting both practices in teachers' current zone of proximal development as well as more reflective practices of the future. Strategically, we need to build tools to support current practice, gain acceptance, and then build on this base to change the practice along with and through the tools. This process could be supported by technology serving as a collaborative workspace with functions to enable socialization and interpersonal connection (Barab, MaKinster, \& Scheckler, 2003).

A related question is how teachers will learn to use technology. We began under the assumption that educators could learn to teach with technology by first learning to learn with technology. However, through surveys and focus groups as well as informal experience we found that HNLC educators tend to view technology as resources for use with their students, and are more likely to be inspired by their students' use of technology than vice-versa. Yet they 
Prepublication draft of Suthers, D., Harada, V., Yukawa, J., \& Lid, V. (2005). "Supporting and changing practices of nested and overlapping educational communities. ACM SIGGROUP Bulletin 24 (3): 90-95.

also acknowledge that technology is an important resource for their own professional development. Perhaps the resolution to this apparent tension between teacher-first versus student-first use is to shape professional development so that participants use the tools in the way students would be asked to use them in inquiry-based learning. They would thereby gain simultaneous training in the practice of inquiry-based learning and the use of technologies as specifically applied to the inquiry activities of themselves and their students.

\section{What do we build?}

We have so far considered what we can do to support present and future practices of multiple communities and teams. A deeper problem arises if many of these communities of practice do not already exist. Then the question becomes, "What do we build - the community, the practice, the tools?" Communities of practice need to be built from a complex array of factors and in a manner that is timely and unique to each group. A community design cannot simply be proffered to a group (Fullan, 1993). Kling and Courtright (2003) contend that it is easier to foster technology supported community development than to nurture technology initiated communities. Communities evolve within groups around their particular needs and for purposes that they value. Program planners must face issues of sociability as well as usability in developing a design that links to and supports people's social interactions (Barab et al., 2003; Preece, 2002). Fostering trusting and respectful relationships is paramount. This is the basis for community building, and, once established, each community of practice then directs the development, adoption, and use of technology for its specific needs. The process combines both bottom-up and top-down efforts to answer the questions we pose here. When multiple, nested communities of practice are involved, our responsibilities for attentiveness and technological responsiveness are correspondingly increased and should be clearly prioritized.

\section{Current Research}

Our continued research is organized around two major issues: (1) technology-supported communities and systemic reform (as discussed above), and (2) the affordances of technology as a mediating artifact in supporting these communities (Suthers, in press). We raise the following questions to guide our investigation. (1) What strategies can encourage time-pressed, technology-hesitant teachers to use technology for their own learning and collaboration? Once technology has been adopted for collaboration, how do the new relationships and communities so formed influence classroom practices towards genuine inquiry? How are new relationships formed via technology or via a mixture of face-to-face and online interactions? Does embedding small groups within the context of a statewide online community lead to the formation and enhancement of small group work? Do technology-mediated groups or communities change the operation of the organization in which they are embedded? (2) How is technology used not only as "communication channel" but also as a medium within which questions and problems are identified and shared solutions are negotiated? How can design of representational notations influence such collaborative inquiry? How can workspaces be adapted to users' needs?

\section{Acknowledgments}

We are grateful to the numerous individuals who have contributed towards HNLC, including Vicki Kajioka (HNLC co-PI and ATRB director), Claudia Atta (HNLC interim project director), and Pat Donohue (former HNLC project director), and the other members of the ATRB and UH teams for their hard work during the period reported in this paper: Malia Chow, Wil Doane, Laura Girardeau, Bruce Harris, Kyle Shodai, Joshua Wingstrom, and Ryan Yoshioka. This work was supported by the National Science Foundation under Cooperative Agreement No. 0100393. Any opinions, findings, and conclusions or recommendations expressed in this paper are those of the authors and do not necessarily reflect the views of the National Science Foundation.

\section{References}

Barab, S. A. (2003). An introduction to the special issue: Designing for virtual communities in the service of learning. The Information Society, 19, 197-201.

Barab, S. A, MaKinster, J. G., \& Scheckler, R. (2003). Designing system dualities: Characterizing a web-supported professional development community. The Information Society. 19, 237-256.

Fullan, M. (1993). Change forces: Probing the depths of educational reform. London: Falmer Press.

Girgensohn, A. \& Lee, A. (2002). Making Web Sites be Places for Social Interaction. Proceedings of CSCW'02, November 16-20, 2002, New Orleans, Louisiana, USA. pp. 136-145. 
Prepublication draft of Suthers, D., Harada, V., Yukawa, J., \& Lid, V. (2005). "Supporting and changing practices of nested and overlapping educational communities. ACM SIGGROUP Bulletin 24 (3): 90-95.

Kelly, S. U., Sung, C. \& Farnham, S. (2002). Designing for Improved Social Responsibility, User Participation, and Content in On-Line Communities. Proceedings of CHI 2002, April 20-25, 2002, Minneapolis, Minnesota, USA. pp. 391-398.

Kling, R., \& Courtright, C. (2003). Group behavior and learning in electronic forums: A sociotechnical approach. The Information Society, 19, 221-235.

McLaughlin, M. W., \& Mitra, D. (2001). Theory-based change and change-based theory: Going deeper, going broader. Journal of Educational Change, 1, 2-24.

Preece, J. (2000). Online Communities: Designing Usability and Supporting Sociability. John Wiley \& Sons.

Resnick, L. B. \& Hall, M. W. (1998). Learning organizations for sustainable educational reform. Daedalus, Journal of the American Academy of Arts and Sciences, 127(4), 89-118.

Soloway, E. (June 1996). Teachers are the key. Communications of the ACM 39(6): 11-14

Stahl, G. (in press). Collaboration with Technology: Mediation of Group Cognition. MIT Press.

Suthers, D. (in press). Technology affordances for intersubjective learning, and how they may be exploited. In Bromme, R., Hesse, F.W. \& Spada, H. (Eds.) Barriers and biases in computer-mediated knowledge communication - and how they may be overcome. Kluwer Academic Publishers/Springer.

Suthers, D., Harada, V., Doane, W., Yukawa, J., Harris, B. \& Lid, V. (2004). Technology-Supported Systemic Reform: An Initial Evaluation and Reassessment. Proceedings of the Sixth International Conference of the Learning Sciences, Santa Monica, CA - June 22-26, 2004. pp. 537-544.

Wenger, E., McDermott, R., \& Snyder, W. (2002). Cultivating communities of practice. Cambridge, MA: Harvard Business School Press. 